\title{
Vulnerability factors for common mental illnesses
}

\section{DAVID GOLDBERG}

\begin{abstract}
Background Twin studies suggest that shared early family environment is of only minor importance in the aetiology of depression, most of the variance being attributable either to genetic or to individual 'non-shared' environmental factors.
\end{abstract}

Aims To examine the respective roles of personality and social experiences on the risk for common mental disorders, with special reference to depression.

\section{Method Analysis of preliminary findings from two large-scale British population surveys: (a) a multi-centre study of general practice patients, and (b)a study of working-class women in Manchester.}

\section{Results (a) Persons recently separated from their partners have raised mean scores for psychological distress, but the relative excess is due entirely to persons with high ratings for introversion; (b) while severe life events were associated with physiological responses characteristic of depression, the probability of experiencing such life events varied between 0.2 monthly for low scorers and 1.5 monthly for high scorers on a vulnerability measure.}

Conclusions Social factors do appear to influence the prevalence of depression, but this effect is not independent of genetically determined vulnerability.

Declaration of interest None.
This paper addresses two themes: how social factors fit into the aetiology of common mental disorders, given that recent research suggests that shared family environment is of little importance in the aetiology of depression (Kendler et al, 1992; Thapar \& McGuffin, 1994; Eley \& Stevenson, 1999); and how genetic factors might exert a role on life events.

In 1987 Kendler and others concluded from a study of Australian twins that:

"there was no evidence for genes affecting depression that did not also affect anxiety. Genetic factors act to influence the general level of symptoms, whereas the environment has specific effects, since some features of the environment strongly influence anxiety while having little effect upon depressive symptoms" (Kendler et al, 1987).

However, the twin studies quoted above found that most of the variance that can be accounted for is attributable to genetic factors and individual or 'non-shared' environmental factors. This may partly be due to the fact that the various twin studies have administered questionnaires and inventories to the twins during their adult lives, when the effects of shared family environment may be expected to be getting weaker. With intellectual ability, for example, it is possible to demonstrate the importance of shared family factors during childhood, but Plomin et al (1997) have shown that these effects are no longer demonstrable by the time adult life has been reached. It seems likely that if early environment is important, as time goes on the influences interact with factors in the individual's life, so entering the analyses as 'non-shared' environment.

Rutter and his colleagues (Rutter et al, 1999) have sounded a note of caution about too literal an interpretation of these findings, arguing that measurement error is included in the assessment of non-shared environment - and this can be considerable; that effects of non-shared environment are less when behaviour is assessed over a longer period; that genetic effects in any case exert their effect by gene-environment interactions; and that there are discrepancies between assessments based on parental report (which generally favour genetic factors) and those based upon measures taken of the children themselves. In short, there are grounds for doubting that the geneticists' results are as clear-cut as they would have us believe.

However, much interest resides in how individuals create their own unique environments, and how genetically determined features interact with the environment: the ' $G \times E$ ' interactions.

\section{FACTORS DETERMINING THE PREVALENCE OF DEPRESSION}

Brown (1998) compared six population surveys in which measures of irregular and disruptive events have been made simultaneously with assessments of the prevalence of depressive illness, and pointed out that there is a strong relationship between the two measures. He considered that genetic factors were unlikely to account for the observed differences in prevalence of depression, and observed that prevalence of depression in a population can alter rapidly, whereas differences in the gene pool would take many years to occur.

One possible way of reconciling Brown's results with those of the behavioural geneticists is to assume that different individuals have very different vulnerabilities to depression, and that the extent to which depression is released in a population is determined by the intensity of social stress impinging on that population.

There is no entirely satisfactory measure of this vulnerability, but the quality described as neuroticism (' $n$ ') by Eysenck (1952) or 'harm avoidance' by Cloninger (1987) comes closest to it. This quality is often referred to as though it were entirely determined by genes at birth, and thereafter does not alter. The longer the time interval between tests, the lower the test-retest correlation (Watson \& Clark, 1984; Ormel \& Rijsdijk, 2000), suggesting a quality that changes with time. Loehlin (1992) has shown that estimates of the heritability of ' $n$ ' are usually only between $40 \%$ and $45 \%$, and the concordance of monozygotic twins reared apart is much less $(0.38 v$. 0.46) than that of monozygotic twins 
reared together - suggesting a strong environmental component (Plomin et al, 1997). Perhaps neuroticism should be thought of as a more or less stable measure of the level of symptoms that have been experienced in the year or two before each test occasion, and it should be acknowledged that changes in life situation can alter the observed level of neuroticism.

None the less, in longitudinal multisweep surveys, measures of neuroticism provide the best prediction of future episodes of depression (Horwood \& Fergusson, 1986; Duncan Jones et al, 1990) and there is an interaction between the level of neuroticism and the intensity of life stress necessary to release an episode of depression (Ormel \& Wohlfarth, 1991). Indeed, if we take into account the fact that genes account for less than half the observed variance of neuroticism, it becomes important to consider what other components contribute to observed neuroticism at any given time - and it is here that social factors take their proper place in the determination of vulnerability.

Early childhood adversity - likely to appear as non-shared environment in genetic studies, as no two people's perceptions of abuse are likely to be the same - becomes important here, as does social disadvantage during adult life. As age advances, it seems probable that early life experience will become less relevant - although if abuse has been severe, it is likely to give rise to a continuous negative interaction with the environment, which will also emerge as non-shared environment in genetic studies.

\section{Personality and life events}

Headey \& Wearing (1989) showed that people tend to experience life events at about the same rate (although there was a decline with age, the rates correlated about +0.50 with one another), and those tending to experience favourable events continued to do so, as did those with unfavourable events. They used a measure called 'openness to experience', which roughly corresponds to the dimension 'culture' in the 'big five' theories (Goldberg, 1990). At one end, there are items such as 'I find it easy to empathise', while at the other end are items such as 'I rarely feel strong emotion'. They showed that favourable event could be predicted by age, extraversion and openness, while unfavourable events were predicted by neuroticism and openness. They went on to show that openness predicted one good quality (friendships) and one bad one (financial problems), so their findings were not so difficult to understand as they might have been. None the less, you will observe that the power to predict frequency of events is only a small one.

The story has been taken forward by Saudino et al (1997) who studied Swedish twins and adoptees. Genetic factors were found to be operating through personality for women, but not for men, whom they thereafter ignored. But the heritabilities of three kinds of life events were high in the female sample. If we ignore desirable life events - as they are not depressogenic - we find that controllable events are predicted somewhat from a common personality measure, and then quite strongly by extraversion, with unique environment contributing the rest of the prediction, although less strongly than extraversion. Undesirable events were predicted by openness, to which genetic factors were making a strong contribution, and by unique environment. Saudino and colleagues did not find that neuroticism was contributing to their measure of life events.

I am at present one of many investigators engaged upon the Genesis Study, originally designed by the late David Fulker. This study selects concordant and discordant sibling pairs from a large series of 26000 respondents drawn from general practice. We eventually hope to establish quantitative trait loci for anxiety and depression, but so far have only completed the pilot study. However, we already have interesting data about the associations of psychological distress with neuroticism on the one hand, and with life events and social adjustment on the other.

Some interesting interactions between distress and personality have become apparent. Those who report a recent separation from their partners have higher distress scores than others; however, there is an interaction with extraversion: there is no significant increase among the extraverts - the effect is entirely due to introverts who have separated.

Two factors account for all the variance worth counting: the first factor, which we can call 'psychological distress', has a high load for General Health Questionnaire (GHQ) score (Goldberg \& Williams, 1988), and almost as high for ' $n$ '. Introversion, three stressful life events, and all our measures of poor social adjustment, all load heavily on this factor. The other, smaller factor has equally high loads for extraversion and sensation-seeking, so we may perhaps call it 'extraversion'. The same three life events load on this factor, but there is much less social maladjustment associated with it.

Multiple regression equations show that our four main personality measures have slightly different variables accounting for them: we can account for $22-24 \%$ of the variance in GHQ score in terms of recent life events - five of these are associated with it - and all our measures of social maladjustment. In contrast, we can only account for $16 \%$ of the variance in neuroticism. Breaking up a relationship now makes its appearance; but only poor housing is as strongly associated with it as with the GHQ.

Extraversion is associated with financial problems, breaking up relationships and loss of a valued object; introversion is associated with problems at work, with relationships and with social life. However, only a small proportion of the variance is accounted for in this way. Sensation-seeking is similar to extraversion; thus, extraversion is making a contribution to life problems that is separate, and different, from factors relating to distress.

Kendler et al (1987) have speculated that perhaps genetic factors exert their effects by increasing sensitivity to life events. Perhaps they do: but the frequency of life events, and their associated life difficulties, must also play their part. One of our patients only experienced an onset of depression after four life difficulties and six life events in the course of a year: this returns us to Brown's point - with sufficiently high levels of social problems, most people will experience an onset. Such problems are more frequently encountered among the poorest and most disadvantaged sections of the population.

\section{Some features of severe life events}

A recently completed large study of workingclass women in Manchester, which included biological measures as well as a full set of social variables, showed that different classes of women experienced different rates of life events. Non-vulnerable women were found to experience life events at a rate of less than 0.2 per month, followed by those with low scores on the vulnerability measure; however, the most vulnerable women were having life events at a rate of 1.5 a month. This study did not replicate the finding of Goodyer et al (1996) that high social stress 
is associated with higher levels of salivary cortisol: only women with the highest levels of social distress on the life events and difficulties schedule (LEDS) interview had higher cortisol levels when depressed. However, severe life events were associated with an increased fenfluramine response and reduced levels of tryptophan (Deakin, 1999).

\section{CONCLUSION}

The conclusions of these disparate strands of evidence are that social factors do seem to have an influence upon prevalence of depression in the population, but that this effect is not independent of genetically determined vulnerability: indeed, it is most likely that the most vulnerable are at greatest risk. However, the concept of vulnerability is by no means determined genetically: less than half the variance can be thought of in this way. Early experiences are indeed contributing to vulnerability, although their effects may become less great as age advances. Severe early aversive events may be responsible for abnormal interactions between the individual and the social environment, and thus enter the 'non-shared' or unique environment studied by geneticists. It is also clear that people create their own environments, and that personality factors other than neuroticism have to be invoked if we are to understand the kinds of stressful life events that are experienced by an individual.

SIR DAVID GOLDBERG, Institute of Psychiatry, De Crespigny Park, London SE5 8AF, UK

\section{REFERENCES}

Brown, G.W. (1998) Genetic and population perspectives on life events and depression. Socia Psychiatry and Psychiatric Epidemiology, 33, 363-372.

Cloninger, C. R. (1987) A systematic method for clinica description and classification of personality variants. Archives of General Psychiatry, 44, 579-588.

Deakin, J. F.W. (1999) Making sense of serotonin and its role in common psychopathology. In Common Mental Disorders in Primary Care (eds M. Tansella \& G. Thornicroft), pp. 17-33. London: Routledge.

Duncan Jones, P., Fergusson, D. M., Ormel, J. H., et al (1990) A model of stability and change in minor psychiatric symptoms - results from 3 longitudinal studies. Psychological Medicine Monograph Supplement, 18, I-28.

Eley, T. C. \& Stevenson, J. (1999) Using genetic analyses to clarify the distinction between depressive and anxious symptoms in children. Journal of Abnormal Child Psychology, 27, 105-114.

Eysenck, H. J. (1952) The Scientific Study of Personality. London: Routledge \& Kegan Paul.

Goldberg, D. P. \& Williams, P. (1988) A User's Guide to the GHQ.Windsor: NFER-Nelson.

Goldberg, L. R. (1990) An alternative description of personality: the big five factor structure. Journal of Personality and Social Psychology, 59, 1216-1229.

Goodyer, I. M., Herbert, J., Altham, P. M. E., et al (1996) Adrenal secretion during major depression in 8 to 16 year olds. Psychological Medicine, 26, 245-256.

Headey, B. \& Wearing, A. (1989) Personality, life events and subjective well being: towards a dynamic equilibrium model. Journal of Personality and Social Psychology, 57, 73I-739.

Horwood, L. J. \& Fergusson, D. M. (1986)

Neuroticism, depression and life events: a structural equation model. Social Psychiatry, 2I, 63-7I.
Kendler, K., Heath, A., Martin, N., et al (1987)

Symptoms of anxiety and symptoms of depression. Archives of General Psychiatry, 122, 45I-457.

_, Neale, M. C., Kessler, R. C., et al (1992) A population based twin study of major depression in women. Archives of General Psychiatry, 49, 257-266.

_, Kessler, R. C., Walters, E. E., et al (1995) Stressful life events, genetic liability, and onset of episodes of major depression in women. American Journal of Psychiatry, 152, 833-842.

Loehlin, J. C. (1992) Genes and Environment in Personality Development. Newbury Park, CA: Sage.

Ormel, J. \& Wohlfarth, T. (1991) How neuroticism, long term difficulties and life situation change influence psychological distress: a longitudinal model. Journal of Personality and Social Psychology, 60, 744-755.

— \& Rijsdijk, F. (2000) Continuing within subject change in neuroticism during adulthood structural modelling of a 16 year, 5 wave community study. Personality and Individual Differences, 28, 46I-478.

Plomin, R., de Fries, J. C., McClearn, G. E., et al (1997) Behavioural Genetics. New York: Freeman.

Rutter, M., Silberg, J., O'Connor, T., et al (1999) Genetics and psychiatry: I. Advances in quantitative and molecular genetics; 2 . Empirical research findings. Journal of Child Psychology and Psychiatry, 40, 3-55.

Saudino, K. J., Pedersen, N. L., Lichtenstein, P., et al (1997) Can personality explain genetic influences on life events? Journal of Personality and Social Psychology, 72 , 196-206.

Thapar, A. \& McGuffin, P. (1994) Anxiety and depressive symptoms in childhood - a genetic study of co-morbidity. Psychological Medicine, 38, 65I-656.

Watson, D. \& Clark, L. A. (1984) Negative affectivity the disposition to experience aversive emotional states. Psychological Bulletin, 96, 465-490. 